\title{
Mejora de la detección del patotipo no defoliante de Verticillium dahliae en olivo mediante PCR anidada
}

Rattalino, D. L., Otero, M. L., Moriconi, D. N. y Rivera, P. C.

DOI: $10.31047 / 1668.298 x . v 38 . n 1.28985$

\section{RESUMEN}

La olivicultura está afectada por un síndrome que genera marchitez en la copa del árbol. Uno de los microorganismos responsables es el hongo Verticillium dahliae, que provoca la enfermedad denominada verticilosis del olivo (VO). Según la severidad de los síntomas, se distinguen dos patotipos, defoliante (D) y no defoliante (ND). Su diagnóstico emplea la reacción en cadena de la polimerasa (PCR). Nuestro objetivo fue comparar la eficiencia de dos juegos de cebadores para detectar en planta el patotipo ND, el único presente en Argentina, mediante PCR anidada. Para ello se utilizaron los juegos de cebadores NDf/NDr - INTND2f/INTND2r (PCR-I), empleados comúnmente, y una nueva combinación, INTNDf/INTNDr - INTND2f/INTND2r (PCR-II). Se analizaron muestras de olivos sintomáticos de 39 fincas de la provincia de La Rioja. PCR-II tuvo mayor eficiencia en la detección, 57,8 \% frente a 16,7 \% de PCR-I. PCR-II amplificó en casi todas las variedades, edades de plantas y niveles de severidad de la enfermedad, mientras que PCR-I detectó el hongo sólo en variedades muy susceptibles y con niveles de severidad leve. El uso de PCR-II para detectar a $V$. dahliae en olivo permitirá estudios más precisos sobre su incidencia que contribuirán al manejo adecuado de la verticilosis.

Palabras clave: verticilosis; diagnóstico molecular; Olea europaea.

Rattalino D. L., Otero, M. L., Moriconi D. N. and Rivera, P. C., 2021. Improved detection of the non-defoliant pathotype of Verticillium dahliae in olive trees using nested PCR. Agriscientia 38: 79-91

\section{SUMMARY}

Olive growing is affected by a syndrome that causes wilt in the tree top. One of the main microorganisms accountable for this disease is the fungus Verticillium dahliae, which causes verticillium wilt (VW). Two pathotypes are distinguished within $V$. dahliae, defoliating (D) and non-defoliating (ND), depending on symptom severity. The pathogen is generally diagnosed by polymerase chain reaction $(\mathrm{PCR})$. Our objective was to compare the efficiency of two sets of 
primers in detecting the ND pathotype in olive plants, the only pathotype found in Argentina, by nested PCR. For this purpose, the commonly used primer combination NDf/NDr - INTND2f/INTND2r (PCR-I) and a new combination, INTNDf/INTNDr - INTND2f/INTND2r (PCR-II), were evaluated. Samples of symptomatic olive trees from 39 commercial fields from La Rioja province were analyzed. PCR-II had higher detection efficiency than PCR-I (57.8\% and $16.7 \%$, respectively). PCR-II amplified in almost all the olive cultivars, plant ages and VW disease severity levels, whereas PCR-I detected the fungus only in very susceptible cultivars and in trees with low VW severity levels. The use of PCR-II for the detection of $V$. dahliae in olive plants will provide more accurate incidence results and will contribute to a proper management of VW.

Keywords: verticillium wilt; molecular diagnosis; Olea europaea.

Rattalino, D. L. (ORCID: 0000-0002-6531-9333) y Moriconi, D. N. (ORCID: 0000-0003-4740-9754): Universidad Nacional de Chilecito, Departamento de Ciencias Básicas y Tecnológicas - Instituto de Ambientes de Montaña y Regiones Áridas (IAMRA). 9 de Julio 22, (F5360CKB), Chilecito, La Rioja, Argentina. Otero, M. L. (ORCID: 0000-0002-3164-3880): Instituto Nacional de Tecnología Agropecuaria (INTA), Instituto de Patología Vegetal, Centro de Investigaciones Agropecuarias (IPAVE-CIAP). Av. 11 de Septiembre 4755, (X5014MGO) Córdoba, Argentina. Universidad Nacional de Córdoba, Facultad de Ciencias Exactas Físicas y Naturales, Unidad de Fitopatología y Modelización Agrícola (UFyMA), INTA-CONICET. Av. 11 de Septiembre 4755, (X5014MGO), Córdoba, Argentina. Rivera, P. C. (ORCID: 00000002-4473-7640): Universidad Nacional de Chilecito, Departamento de Ciencias Básicas y Tecnológicas - Instituto de Ambientes de Montaña y Regiones Áridas (IAMRA). 9 de Julio 22, (F5360CKB), Chilecito, La Rioja, Argentina. Instituto de Diversidad y Ecología Animal (IDEA), CONICET-UNC. Av. Vélez Sársfield 299, (X5000JJC), Córdoba, Argentina. Correspondencia a: drattalino@undec.edu.ar

\section{INTRODUCCIÓN}

La olivicultura en una importante actividad comercial en la Argentina, siendo este país el principal productor de aceitunas de mesa y aceite en Latinoamérica (Gómez Del Campo, MoralesSillero, Vita Serman, Rousseaux y Searles, 2010). El $90 \%$ de la producción del país se concentra en las regiones áridas y semiáridas de las provincias de Catamarca, La Rioja, San Juan y Mendoza (Searles et al., 2012). La actividad olivícola se ve amenazada aquí, al igual que en otras regiones del mundo, por la verticilosis del olivo (VO) (López-Escudero y Mercado-Blanco, 2011; Jiménez-Díaz et al., 2012). Ésta es una enfermedad vascular provocada por el hongo habitante de suelo Verticillium dahliae Kleb., que genera grandes pérdidas económicas en olivares de todo el mundo. La enfermedad se manifiesta en estos árboles con un decaimiento lento, hojas que adquieren una tonalidad verde seco a marrón y se enrollan, coloración castaña a rojiza de las ramas y marrón en los vasos del xilema, defoliación parcial o completa y marchitez y necrosis de hojas, ramas e inflorescencias. Estos síntomas se observan en la copa de manera parcial o total y pueden ocasionar la muerte del árbol (López-Escudero y Mercado-Blanco, 2011; Jiménez-Díaz et al., 2012). Se distinguen dos razas o patotipos de $V$. dahliae, de acuerdo con la severidad de los síntomas y según produzcan o no defoliación de las hojas verdes (Schnathorst y Sibbett, 1971). El patotipo no defoliante (ND) es de virulencia moderada y se encuentra ampliamente distribuido en todo el mundo, mientras que el patotipo defoliante (D) es de virulencia severa, y se encuentra difundido en el sur de España, Grecia e Italia, entre otros países (López-Escudero y Mercado-Blanco, 2011; Jiménez-Díaz et al., 2012). Se han observado también casos de severidad intermedia que causan defoliación 
parcial en algodón y otros cultivos, denominado defoliating-like (DL) aunque no ha sido probada su patogenicidad en olivo (Korolev, Katan y Katan, 2000).

El mecanismo de infección de $V$. dahliae consiste en la penetración de las hifas en la raíz en forma directa o a través de heridas, seguida de la colonización de la corteza e invasión de los vasos del xilema, donde puede permanecer por largos períodos sin causar síntomas aparentes de enfermedad (Rodríguez-Jurado, 1993; Pegg y Brady 2002). Los síntomas de marchitez se originan por el crecimiento de las hifas del hongo conjuntamente con sustancias de defensa producidas por el hospedero que bloquean los vasos del xilema (Hiemstra y Harris, 1998; Pegg y Brady, 2002). El diagnóstico de la enfermedad causada por $V$. dahliae basado sólo en los síntomas no es confiable, debido a que la sintomatología aérea de desecación y marchitez es inespecífica. Esta sintomatología es similar a la observada en árboles con estrés hídrico (Hiemstra y Harris, 1998) o que presentan enfermedades generadas por otros patógenos como la bacteria Xylella fastidiosa Wells (Saponari, Boscia, Nigro y Martelli, 2013; Haelterman et al., 2015), hongos habitantes de suelo como Fusarium spp. (Pérez et al., 2001; Pérez Farinon y Berretta, 2011) y oomycetes como Pythium spp. (Sánchez-Hernández, Pérez De Algaba, Blanco-López y Trapero-Casas, 1998; Lucero et al., 2005) y Phytophthora spp. (Lucero, Vettraino, Pizzuolo, Stefano y Vannini, 2007; Chliyeh et al., 2014; Lucero, Pizzuolo, Boiteux y Hapon, 2014). Por ello, se considera que el síndrome puede ser ocasionado por un complejo de patógenos y se lo denomina seca de olivos jóvenes (SOJ) en España (Sánchez-Hernández et al., 1998) y rama seca en Argentina (Pérez et al., 2001; Roca et al., 2001; Roca, 2015). Este complejo incluye a V. dahliae como uno de los organismos causales más importantes del síndrome.

En la actualidad, no existe un método de control eficaz para tratar la $\mathrm{VO}$, sino que se utilizan diferentes estrategias para prevenir o disminuir su incidencia, aunque con resultados aleatorios (López-Escudero y Mercado-Blanco, 2011; Jiménez Díaz et al., 2012). Por ello es indispensable contar con un método de diagnóstico específico para detectar al hongo en forma rápida y precisa. La metodología más comúnmente empleada para la detección de $V$. dahliae consiste en el aislamiento del patógeno a partir de muestras de tejido xilemático, principalmente de raíces y ramas de plantas sintomáticas, y la posterior identificación morfológica de las colonias desarrolladas utilizando lupa y microscopio (Docampo, Vázquez y Laguna, 1981; Jiménez-Díaz et al., 2012). Esta técnica es dificultosa y lenta, ya que deben hacerse varias repeticiones por muestra, lo que no resulta práctico cuando el volumen de muestras es elevado; además requiere un mínimo de siete días de crecimiento de la colonia del hongo para la identificación de sus estructuras reproductivas características y está limitada a las épocas del año donde el hongo se encuentra activo (LópezEscudero y Mercado-Blanco, 2011; Jiménez-Díaz et al., 2012). Asimismo, resulta poco efectiva, ya que el éxito de aislamiento es bajo en leñosas como el olivo, dependiendo del grado de colonización, la patogenicidad de la cepa, el sector de la planta muestreado y la susceptibilidad de la variedad analizada (López-Escudero y Mercado-Blanco, 2011; Jiménez-Díaz et al., 2012). Otra desventaja que presenta esta técnica es que no provee información sobre la identidad del patotipo de las cepas aisladas, sino que requiere la realización de pruebas de patogenicidad en hospedantes o de pruebas de crecimiento in vitro (Docampo et al., 1981; Otero, 2005).

Con el desarrollo de las técnicas moleculares surgieron distintos ensayos basados en la reacción en cadena de la polimerasa (Polymerase Chain Reaction o PCR por sus siglas en inglés) para identificar aislados de $V$. dahliae obtenidos a partir de muestras de olivo (Nazar, Hu, Schmidt, Culham y Robb, 1991; Pérez-Artés, García-Pedrajas, Bejarano-Alcázar y Jiménez-Díaz, 2000; Collins et al., 2005; Keykhasaber, 2017). Cuando se busca detectar al hongo en muestras de tejidos vegetales aumenta la complejidad de la técnica, en particular en el caso de las leñosas, ya que la cantidad de ADN del hongo disponible en la muestra es muy baja en comparación a la cantidad de ADN de la planta y esto dificulta su detección (Mercado-Blanco, Rodríguez-Jurado, PérezArtés y Jiménez-Díaz, 2001; Mercado-Blanco, Rodríguez-Jurado, Parrilla-Araujo y Jiménez-Díaz, 2003b; Ma y Michailides, 2007). Además, aun cuando el ADN de las muestras se haya extraído exitosamente, éstas pueden presentar inhibidores propios de las plantas, muy frecuentes en leñosas, como polisacáridos y compuestos fenólicos que interfieren con la amplificación (Wilson, 1997). Por ello, para incrementar la sensibilidad y la especificidad de la detección, se realizan PCR anidadas, es decir, dos rondas de amplificación con distintos pares de cebadores en cada una. Primero se lleva a cabo una reacción con los cebadores externos para amplificar una región de ADN. Después, este producto se utiliza como molde de una segunda PCR con los cebadores internos para amplificar una región más pequeña. 
Los cebadores más utilizados para identificar las cepas aisladas y para la detección en planta del hongo fueron diseñados por Mercado-Blanco, Rodríguez-Jurado, Pérez-Artés y Jiménez-Díaz (2002) y Mercado-Blanco et al. (2001) a partir de la secuencias de un fragmento de ADN nuclear específico de las cepas D y otro de las cepas ND de $V$. dahliae obtenidas de olivos de España (Pérez-Artés et al., 2000). En su trabajo, MercadoBlanco et al. (2001) desarrollaron tres pares de cebadores que se unen al fragmento de las cepas ND. El par externo (NDf/NDr) amplifica una banda de $1410 \mathrm{pb}$, el segundo (INTNDf/INTNDr), una banda de 1163 pb y el tercero (INTND2f/INTND2r), una banda de $824 \mathrm{pb}$. El primero se une a regiones no codificantes y los últimos dos (internos) a una región codificante, que posiblemente presente una menor tasa de variabilidad que las regiones no codificantes. A pesar de esto, la combinación de cebadores más difundida para realizar PCR anidada es la del par externo (NDf/NDr) y el más interno (INTND2f/INTND2r), la cual se ha utilizado para detectar e identificar al patotipo ND de $V$. dahliae en olivos y algodones de España, Italia e Israel (Mercado-Blanco, Rodríguez-Jurado, ParrillaAraujo, y Jiménez-Díaz, 2003a; Mercado-Blanco et al., 2003b; Collins et al., 2005; Mercado-Blanco, Collado-Romero, Rodríguez-Jurado y JiménezDíaz, 2005; Collado-Romero, Berbegal, JiménezDíaz, Armengol y Mercado-Blanco, 2009), Grecia (Keykhasaber, 2017) y Tunisia (Gharbi et al., 2014).

En Argentina, $V$. dahliae ha sido detectado principalmente mediante métodos microbiológicos en olivares de las provincias de Córdoba, Catamarca, Mendoza y La Rioja (Docampo et al., 1981; Otero, 2005; Pérez et al., 2010; Ladux, Jotayan, Otero, González Vera y Ortiz, 2014; Roca, 2015; González et al., 2017; Rattalino et al., 2018). Los estudios sobre la identificación y diagnóstico molecular de este patógeno son escasos a nivel regional, habiéndose realizado la detección en plantas de olivo mediante PCR en tres estudios (Otero, 2005; Roca, 2015; Rattalino et al., 2018). Las cepas de $V$. dahliae obtenidas de olivo y algodón fueron identificadas como pertenecientes al patotipo ND (Docampo et al., 1981; Otero, 2005; González et al., 2017; Rattalino et al., 2018); por lo que hasta el momento, no se ha detectado la cepa $\mathrm{D}$ en Argentina. En particular, en la provincia de La Rioja la VO ha tomado gran relevancia en los últimos años, debido a la creciente preocupación por el avance de la enfermedad y los daños ocasionados en las plantaciones (Ladux et al., 2014). A causa de esto, el gobierno provincial promulgó las leyes No 8.804 (año 2010) y $N^{\circ}$ 9.489 (año 2013) de emergencia fitosanitaria y de zona de desastre agropecuario, respectivamente, existiendo una fuerte demanda de investigaciones sobre diferentes aspectos de la VO. La evidencia disponible acerca de la presencia de $V$. dahliae en la región no concuerda con la magnitud de la problemática observada a campo; esto puede deberse a la dificultad en la obtención de aislados del hongo y a la baja detección a través de los métodos moleculares disponibles para el diagnóstico en planta. Ante la necesidad de disponer de un método de detección molecular sensible y eficiente, el objetivo de este trabajo fue comparar la detección en planta del patotipo ND de dos juegos de cebadores en pruebas de PCR anidada: PCR-I, con los cebadores empleados comúnmente (NDf/NDr - INTND2f/INTND2r), y PCR-II con una nueva combinación (INTNDf/ INTNDr - INTND2f/INTND2r). El estudio se realizó en olivos sintomáticos de plantaciones de la provincia de La Rioja.

\section{MATERIALES Y MÉTODOS}

\section{Sitio de muestreo y obtención del material biológico}

Durante los años 2014 a 2017 se relevaron 39 fincas seleccionadas al azar, con sistemas de manejo moderno (marco de plantación inferior a $10 \times 10$ m, conducción en vaso o seto, adaptable a cosecha mecánica) o tradicional (marco de plantación de $10 \times 10$ m, conducción en vaso y cosecha manual), en los departamentos Chilecito, Arauco y Capital de la provincia de La Rioja. La toma de muestras se realizó entre los meses de septiembre y mayo, principalmente en primavera, dado que además de ser el período de crecimiento vegetativo de la planta, es la época más favorable para el desarrollo del hongo, evitando temperaturas mayores a $30^{\circ} \mathrm{C}$ en las cuales se inactiva (Montes, Páez, Vega y Duhart, 1997; Tosi y Zazzerini, 1998; Jiménez-Díaz et al., 2012). Se recorrió un lote en fincas con menos de 150 ha y dos en fincas con más de 150 ha. Los lotes dentro de cada finca también fueron seleccionados al azar. En cada uno, se realizó una transecta en forma de W iniciando en un extremo de este. Se evaluó el estado fitosanitario del primer olivo de la fila y se continuó de forma secuencial cada cinco ejemplares en las fincas tradicionales y cada diez en las modernas. En cada transecta se tomaron muestras solamente de los árboles que presentaron sintomatología típica de VO: decaimiento lento, marchitez o defoliación parcial de la copa, abarquillamiento de hojas con tonalidad verde seco a marrón, coloración castaña a rojiza de las ramas y vasos del xilema o marchitez 
y necrosis de hojas, ramas e inflorescencias. De cada uno de estos olivos se seleccionaron siete a diez ramas afectadas de distintos sectores de la copa, según indica Keykhasaber (2017), que constituyeron una muestra por árbol. Estas fueron almacenadas en bolsas plásticas y llevadas al laboratorio donde se guardaron a $4{ }^{\circ} \mathrm{C}$ hasta su procesamiento. Se identificó la variedad de cada olivo muestreado y se lo clasificó según la edad de la planta en cuatro categorías: 1-10, 11 a 25, 26 a 50 y más de 50 años de edad; y según el nivel de severidad, determinado mediante observación visual siguiendo la escala establecida por LópezEscudero y Mercado-Blanco (2011) donde 1= 1 a $25 \% ; 2=26$ a $50 \%$; $3=51$ a $75 \%$ y $4=76$ a $100 \%$ de tejido foliar afectado.

\section{Detección microbiológica de V. dahliae en muestras de olivos}

Para el aislamiento del patógeno de cada muestra se procedió como lo indica Otero (2005), con modificaciones. Se seleccionó un segmento de 20 a $30 \mathrm{~cm}$ por rama (cinco ramas/muestra). Estos fueron lavados bajo agua corriente con una esponja y unas gotas de detergente neutro y se desinfectaron con una dilución al $2 \%$ de hipoclorito de sodio (0,5 g/L; grado técnico) por 3 min. Luego se los colocó bajo agua corriente durante $45 \mathrm{~min}$ para su enjuague. Posteriormente, en campana de flujo laminar, se retiró la corteza y se extrajeron escamas de tejido xilemático abarcando la zona de avance del hongo, pero sin incluir tejido seco. Las escamas fueron desinfectadas con una dilución de hipoclorito de sodio al 20 \% (5 g/L; grado técnico) por $30 \mathrm{~s}$, se enjuagaron dos veces con agua destilada estéril y se secaron sobre papel de filtro esterilizado. Inmediatamente se sembraron cinco a ocho escamas en medio agar papa glucosado (APG, Britannia) con agar agar (AA) en una relación 4:1 P/P y antibiótico (estreptomicina 0,5\% P/V). De cada muestra, se realizaron cinco repeticiones. Los cultivos fueron incubados a $25^{\circ} \mathrm{C}$ en oscuridad durante siete a diez días. Los aislados fúngicos fueron identificados por sus características macro y microscópicas mediante la observación de conidióforos verticilados y microesclerocios bajo lupa y microscopio, según la descripción de Smith (1965). Posteriormente fueron conservados en glicerol al $20 \%$ a $-20{ }^{\circ} \mathrm{C}$.

\section{Obtención del ADN de muestras de olivo y de V. dahliae}

La extracción del ADN total de las plantas se realizó a partir del tejido xilemático según el protocolo de Milligan (1992) por el método CTAB con modificaciones. Para ello, se seleccionó un segmento de 20 a $30 \mathrm{~cm}$ por rama (tres a cinco ramas/muestra), se les extrajo la corteza y con un bisturí esterilizado se tomaron aproximadamente 100 mg de escamas de tejido xilemático. La muestra compuesta se guardó en un microtubo rotulado a $-20{ }^{\circ} \mathrm{C}$ hasta su utilización. Para la extracción de ADN se molieron $50 \mathrm{mg}$ de muestra en nitrógeno líquido y se los colocó en un microtubo al que se le agregó $700 \mu \mathrm{l}$ de buffer de extracción CTAB 2X (CTAB 2 \% P/N, 0,1 M Tris Cl pH 8.0, 20 mM EDTA y $1,4 \mathrm{M} \mathrm{CINa}$ ) junto con bisulfito de sodio (20 g/L). Se adicionaron $20 \mu$ de proteinasa $\mathrm{K}(20 \mathrm{mg} / \mathrm{ml})$ y se lo incubó en baño térmico a $65^{\circ} \mathrm{C}$ por $90 \mathrm{~min}$. Luego se incorporaron $10 \mu \mathrm{l}$ de ARNasa $(10 \mathrm{mg} / \mathrm{ml})$ y se incubó por 30 min a $37^{\circ} \mathrm{C}$. Se agregó un volumen de fenol/cloroformo/alcohol isoamílico (25:24:1), se mezcló por inversión 1 min y se centrifugó a 10.000 rpm por $15 \mathrm{~min}$. Se recuperó el sobrenadante y se le agregó un volumen de cloroformo/alcohol isoamílico (24:1), se mezcló por inversión 1 min y se centrifugó a 10000 rpm por 5 min. Se tomó nuevamente el sobrenadante y se incorporó acetato de sodio ( $0,1 \mathrm{vol} ; 3 \mathrm{M}$ ) y etanol frío (2,5 vol; $100 \%$ ), mezclando por inversión. Luego de $1 \mathrm{~h}$ en freezer a $-20{ }^{\circ} \mathrm{C}$, se centrifugó a $14000 \mathrm{rpm}$ y $-4^{\circ} \mathrm{C}$ por 20 min. Se eliminó el sobrenadante y se lavó el precipitado agregando etanol frío ( $1 \mathrm{ml} ; 70 \%$ ). Se agitó suavemente y se volvió a centrifugar a 14000 rpm y a $-4{ }^{\circ} \mathrm{C}$ por $20 \mathrm{~min}$. El sobrenadante final fue eliminado y se secó el precipitado en estufa a $37^{\circ} \mathrm{C}$, que luego fue rehidratado en $50 \mu \mathrm{l}$ de agua ultrapura estéril (ADE).

Además, se extrajo ADN de los aislados de $V$. dahliae obtenidos en este estudio, de una muestra del patotipo ND (raza SS4) (suministrado por el Dr. M. Blanco López de la Universidad de Córdoba, Córdoba, España) y de cuatro aislados (1_Cat, 24_LR, 613_LR y 684_LR) provenientes de olivares de distintas provincias de Argentina, previamente identificados como ND (González et al., 2017), pertenecientes a la colección conjunta del Instituto de Patología Vegetal, Centro de Investigaciones Agropecuarias (IPAVE-CIAP) y del Laboratorio de Biología Molecular de la Universidad Nacional de Chilecito (LAC-UNdeC). Previo a la extracción, cada aislado fue sembrado con cuatro discos de APG colonizados con micelio de 48-72 h de crecimiento, en un Erlenmeyer con $50 \mathrm{ml}$ de medio caldo de papa glucosado (CPG, 20 \% P/N). Luego se los cultivó en condiciones de oscuridad, agitación continua a 800 rpm y temperatura ambiente durante siete días (LópezEscudero, del Río, Caballero y Blanco-López, 
2004). Posteriormente fueron centrifugados, fraccionados y liofilizados, y a partir de ese material se aplicó el mismo protocolo de extracción de ADN que para las muestras de olivos, sin el uso de bisulfito de sodio. La calidad y concentración del ADN obtenido se evaluó en geles de agarosa $1 \%$ en TBE 0,5X mediante comparación visual con el marcador de peso molecular $\lambda$ DNA/HindIII (Thermo Scientific, Lituania), de concentración conocida. La visualización y fotografiado de los geles, teñidos con GelRed ${ }^{\circledR}$, se realizó bajo luz UV $\left(260 \mathrm{~nm}\right.$ ) usando transiluminador (UVP ${ }^{\circledR}$ BioDocIt ${ }^{\mathrm{TM}}$ Transiluminator, Estados Unidos). A partir de estas muestras se realizaron diluciones de ADN de $20 \mathrm{ng} / \mathrm{\mu l}$.

\section{Ensayo de prueba de inhibición de PCR}

Para descartar falsos negativos por inhibición de la PCR en las muestras del ADN genómico total de olivo, debido a restos de metabolitos secundarios propios del tejido vegetal, como fenoles y taninos, se llevaron a cabo pruebas de PCR según protocolo modificado de Ma y Michailides (2007). Para ello se realizaron amplificaciones con los cebadores específicos para olivo trnTf: 5'-CTACCACTGAGTTAAAAGGG-3' y trnLr: 5'-TCTACCGATTTCGCCATATC-3' (Intrieri, Muleo y Buiatti, 2007) que amplifican un fragmento de 773 pares de bases de la región IGS del ARNt del cloroplasto. Las amplificaciones se realizaron según las especificaciones de ciclado descritas por los autores, con las siguientes modificaciones en las condiciones de la reacción: en un volumen final de $25 \mu \mathrm{l}$, se utilizaron Taq ADN polimerasa $(0,15 \mathrm{U}$; Promega), $1 \mu \mathrm{l}$ de los cebadores (10 $\mathrm{mM}$ ) y 0,5 a $1 \mu \mathrm{l}$ de ADN total de olivo (5-20 ng). La desnaturalización inicial se redujo a 2 min, la extensión a 1 min y la desnaturalización a $30 \mathrm{~s}$. Todas las reacciones contaron con un control negativo ( $A D E$, sin ADN) y un control positivo con ADN de olivo. Las muestras que no lograron ser amplificadas fueron descartadas para el ensayo posterior.

\section{Detección molecular de $V$. dahliae en muestras de olivos}

Las muestras fueron analizadas mediante PCR anidada con los juegos de cebadores de Mercado-Blanco et al., (2001), detallados en la Tabla 1. Todos los cebadores utilizados en este estudio fueron sintetizados por Operon (Estados Unidos), provistos por Tecnolab S. A. (Buenos Aires, Argentina).

Las condiciones de reacción y de ciclado en ambas pruebas (PCR-I y PCR-II) se realizaron según la descripción de Mercado-Blanco et al. (2001), con modificaciones. Para estandarizar y optimizar el método de detección, se realizaron ensayos preliminares de amplificación con modificaciones en la concentración de cloruro de magnesio (15 mM; 20 mM; 25 mM) y de los cebadores (10 $\mathrm{mM} ; 25 \mathrm{mM}$ ). Finalmente, se utilizaron para el mix de reacción Taq ADN polimerasa (0,15 U; Promega), cebadores $(10 \mathrm{mM})$, dNTPs $(20 \mathrm{mM})$, cloruro de magnesio $(25 \mathrm{mM})$ y ADN total de olivo (0,5 a $1 \mu \mathrm{l} ; 5$ a $20 \mathrm{ng}$ ). La desnaturalización inicial fue de $2 \mathrm{~min}$, la desnaturalización y la extensión en cada ciclo de 45 s y 2 min, respectivamente.

Se realizaron dos ensayos de PCR anidada. La PCR-I incluyó los cebadores externos NDf/NDr para la primera ronda de amplificación y los cebadores internos INTND2f/INTND2r, con 1 ul del producto de la primera reacción como ADN molde para la segunda ronda. La PCR-II incluyó como cebadores externos INTNDf/INTNDr para la primera ronda de amplificación y como cebadores internos INTND2f/ INTND2r para la segunda ronda, con las mismas condiciones. Cada ensayo de PCR incluyó un control negativo absoluto (ADE; sin ADN), un control negativo de tejido de olivo, analizado en pruebas anteriores y determinado como sano por el Instituto de Patología Vegetal (IPAVE-CIAP-Córdoba) y un control positivo con ADN de micelio de $V$. dahliae del patotipo ND (raza SS4) y/o de aislados del hongo de la colección antes mencionada. Para cada combinación de cebadores y para todas las muestras analizadas, los ensayos de PCR se

Tabla 1. Secuencia de los cebadores utilizados en las pruebas de PCR anidada

\begin{tabular}{|c|c|c|}
\hline Nombre del cebador & Secuencia de nucleótidos $5^{\prime}-3^{\prime}$ & Tamaño del amplificado \\
\hline NDf & ATCAGGGGATACTGGTACGAGA & \multirow{2}{*}{$1410 \mathrm{pb}^{\mathrm{a}}$} \\
\hline $\mathrm{NDr}$ & GAGTATTGCCGATAAGAACATG & \\
\hline INTNDf & CCACCGCCAAGCGACAAGAC & \multirow{2}{*}{$1163 \mathrm{pb}$} \\
\hline INTNDr & TAAAACTCCTTGGGGCCAGC & \\
\hline INTND2f & CTCTTCGTACATGGCCATAGATGTGC & \multirow{2}{*}{824 pb } \\
\hline INTND2r & CAATGACAATGTCCTGGGTGTGCCA & \\
\hline
\end{tabular}

Referencias:apb: pares de bases de nucleótidos. 
repitieron al menos una vez. Los productos de PCR obtenidos se visualizaron en geles de agarosa al $1,5 \%$ en TBE 0,5X, teñidos con GelRed ${ }^{\circledR}$, en transiluminador (UVP ${ }^{\circledR}$ BioDoc-It ${ }^{\mathrm{TM}}$ Transiluminator, Estados Unidos). El tamaño de los fragmentos obtenidos se calculó por comparación visual con marcadores de peso molecular $1 \mathrm{~kb}$ y $100 \mathrm{pb}$.

\section{Determinación del límite de detección del ADN de V. dahliae}

Para determinar la cantidad mínima de ADN de $V$. dahliae que podría detectarse en muestras de olivos infectados, se realizaron los protocolos de PCR anidada descritos anteriormente utilizando diluciones seriadas $1: 10$, desde $20 \mathrm{ng} / \mathrm{\mu l}$ hasta 0,02 $\mathrm{pg} / \mathrm{\mu l}$ de ADN de $V$. dahliae puro extraído del aislado 1_Cat (Catamarca, Argentina, perteneciente a la colección mencionada anteriormente). Posteriormente, se realizó una mezcla de $1 \mu \mathrm{l}$ de ADN de olivo (20 $\mathrm{ng} / \mathrm{\mu l}$ ) diagnosticadas como sanas y $1 \mu \mathrm{l}$ de ADN del hongo de cada una de las diluciones. Ambas series fueron repetidas al menos dos veces. La concentración del ADN del cual se partió para ajustar las diluciones se midió mediante espectrofotómetro (Thermo Scientific NanoDrop ${ }^{\text {TM }} 1000$ Spectrophotometer, Estados Unidos). En estos ensayos se utilizaron los mismos controles negativos y positivos que se describen en la sección anterior.

\section{Análisis estadísticos}

Se comparó la eficiencia de las combinaciones PCR-I y PCR-II considerando que la variable de respuesta es binaria. Para ello se construyó una tabla de contingencia a dos vías de clasificación, donde la hipótesis nula plantea que ambos juegos de cebadores (PCR-I y PCR-II) amplifican con la misma eficiencia, mientras que la hipótesis alternativa plantea que no amplifican igual. Se usaron los estadísticos Chi cuadrado y McNemar y se calcularon las probabilidades condicionales (valores $\mathrm{p}$ ) asociadas.

Para evaluar los posibles efectos de la edad, severidad y variedad sobre la eficiencia de cada PCR se empleó una regresión logística. Se consideró a la variedad como variable clasificatoria. La severidad y la edad fueron consideradas como regresoras con cuatro estados para la severidad y cuatro para la edad. La variable respuesta fue la amplificación del PCR-I o PCR-II, que tiene dos estados posibles, uno (amplificación) o cero (falta de amplificación). Todos los análisis se realizaron con el software estadístico InfoStat (Di Rienzo et al., 2019).

\section{RESULTADOS Y DISCUSIÓN}

Durante el período vegetativo de primavera y otoño, entre los años 2014 a 2017, se detectó a $V$. dahliae en distintas variedades de olivo en fincas de los departamentos Capital, Chilecito y Arauco (provincia de La Rioja, Argentina) en árboles con síntomas de rama seca. A través del método microbiológico sólo se obtuvieron cuatro aislados de $V$. dahliae de todas las muestras analizadas; dos pertenecientes al departamento Capital, uno a Chilecito y uno a Arauco. La baja efectividad del método, coincide con lo observado en otros trabajos en donde el patotipo ND es dificultoso de aislar, y se encuentra en menor concentración en la planta que el patotipo más severo (D) (Hiemstra y Harris, 1998; Tosi y Zazzerini, 1998; Mercado-Blanco et al., 2003a; López-Escudero et al., 2004; Markakis, Tjamos, Antoniou, Paplomatas y Tjamos, 2009).

En el ensayo de prueba de inhibición para PCR con los cebadores específicos para olivo amplificaron 90 muestras. Se obtuvieron detecciones positivas para el hongo $V$. dahliae en 52 de esas muestras. Los resultados fueron diferentes para cada uno de los juegos de cebadores probados y los porcentajes de detección del hongo aumentaron considerablemente cuando se empleó la combinación de cebadores de PCR-II. Del total de muestras $(n=90)$, el $16,7 \%$ resultó positivo con PCR-I, mientras que con PCR-II se obtuvo un 57,8 \% de amplificaciones, es decir que esta última prueba resultó dos veces y media más eficiente en la detección del hongo. La tabla de contingencia arrojó un valor $p<0,0001$ para el estadístico de McNemar con lo cual se concluye que hay diferencias significativas en la eficiencia de los cebadores, siendo el PCR-II más eficiente que PCR-I. Cabe destacar que todas las muestras que amplificaron con el PCR-I lo hicieron con el PCR-II. Hasta el momento, en la bibliografía existente sobre el tema sólo se había empleado la combinación NDf-NDr/INTND2f-INTND2r (PCR-I) para la detección de $V$. dahliae. La diferencia en la amplificación entre las pruebas PCR-I y PCR-II puede deberse a que los cebadores externos del ensayo PCR-I hibridan en regiones no codificantes del ADN, que presentarían una alta tasa de mutación y por lo tanto es factible que ocurran cambios que modifiquen la capacidad de unión de los cebadores. En cambio, los cebadores INTNDfINTNDr y INTND2f-INTND2r (PCR-II) se unen a una región codificante que presentaría una menor tasa de mutación.

Verticillium dahliae no fue amplificado con ninguna de las dos pruebas en un 42,2 \% de las muestras analizadas a pesar de que todas 
provenían de olivos sintomáticos. Estos resultados podrían indicar la presencia de otro agente causal para el síndrome de rama seca o una falta de amplificación por bajas concentraciones de ADN del hongo en los tejidos de la planta. Keykhasaber (2017) indicó que la biomasa del patógeno, y por ende su ADN, se encuentra en cantidades muy variables dentro de los órganos infectados de la planta y en ocasiones, éste puede no ser detectado. Esto ocurre porque la colonización del hongo se ve limitada dentro del tejido del hospedador por obstrucciones de los vasos como mecanismo de defensa de la planta ante la presencia del patógeno (Hiemstra y Harris, 1998; Pegg y Brady, 2002). Por otro lado, diversos autores han indicado que la biomasa del hongo va decreciendo en los tejidos de la planta a medida que transcurre tiempo desde la infección, debido al fenómeno de lisis o degradación como parte de los mecanismos de defensa de la planta (Rodríguez-Jurado, Blanco-López, Rapoport y Jiménez-Díaz, 1993; Mercado-Blanco et al., 2001; Mercado-Blanco et al., 2003a; Báidez, Gómez, Del Río y Ortuño, 2007; Markakis et al., 2009). En este sentido, numerosos estudios de detección en planta emplean plantines de vivero inoculados artificialmente y realizan la toma de muestra poco tiempo después de la inoculación (Blanco-López, Jiménez-Díaz y Caballero, 1984; RodríguezJurado et al., 1993; Heinz, Lee, Saparno, Nazar y Robb, 1998; Tosi y Zazzerini, 1998; MercadoBlanco et al., 2001; Mercado-Blanco et al., 2002; Mercado-Blanco et al., 2003a; Mercado-Blanco et al., 2003b). A diferencia de estos antecedentes, el presente estudio se destaca en que se realizó la detección de $V$. dahliae en plantas de olivos adultos de plantaciones comerciales infectados naturalmente.

El muestreo comprendió nueve variedades y una categoría sin identificar (Tabla 2), lo que refleja la diversidad de genotipos de olivo presente en la provincia de La Rioja. Esta heterogeneidad puede asociarse a la implantación y desarrollo de nuevos olivares y a la importación de grandes cantidades de plantines de distintos países, que tuvieron lugar en las últimas tres décadas, propiciados por la Ley de Diferimiento Impositivo (Ley N 22.021) (Gómez del Campo et al., 2010; Matías et al., 2010). La mayoría de las variedades de olivo analizadas aquí fueron señaladas en la bibliografía como susceptibles o muy susceptibles a V. dahliae (López-Escudero, Martos-Moreno, Raya-Ortega y Blanco-López, 2005; Matías et al., 2010; López-Escudero y Mercado-Blanco, 2011). La susceptibilidad se relaciona con los distintos niveles de expresión de los mecanismos de defensa físicos y bioquímicos que posee cada variedad, los cuales permiten diferentes grados de desarrollo del hongo dentro de la planta (Báidez et al., 2007; Trapero, Rallo, López-Escudero, Barranco y Díez, 2015; Keykhasaber, 2017). Nuestros resultados muestran que PCR-II amplificó en la mayoría de las muestras independientemente de la variedad analizada. Mientras que la prueba PCR-I sólo detectó el hongo en las variedades Arauco, Picual y Manzanilla, además de la variedad no identificada (Tabla 2). Cabe destacar que las dos primeras son consideradas extremadamente susceptibles y la variedad Manzanilla susceptible.

Tabla 2. Número de muestras positivas y porcentaje de detección, según la variedad de olivo muestreados, obtenidos con las combinaciones PCR-I y PCR-II

\begin{tabular}{|c|c|c|c|c|c|c|}
\hline Variedad & Susceptibilidad & $\begin{array}{c}\mathrm{N}^{\circ} \text { de } \\
\text { muestras }\end{array}$ & $\begin{array}{l}\mathrm{N}^{\circ} \text { de muestras } \\
\text { positivas PCR-I }\end{array}$ & $\begin{array}{l}\text { Detección (\%) } \\
\text { PCR-I }\end{array}$ & $\begin{array}{l}\mathrm{N}^{\circ} \text { de muestras } \\
\text { positivas PCR-II }\end{array}$ & $\begin{array}{l}\text { Detección } \\
\text { (\%) PCR-II }\end{array}$ \\
\hline Arauco & $\mathrm{ES}^{\mathrm{a}}$ & 43 & 9 & 20,93 & 22 & 51,16 \\
\hline Manzanilla & $S^{a, b}$ & 18 & 4 & 22,22 & 14 & 77,78 \\
\hline Picual & $E S^{a, b} / S^{b}$ & 10 & 1 & 10,00 & 6 & 60,00 \\
\hline $\mathrm{s} / \mathrm{i}$ & - & 7 & 1 & 14,29 & 5 & 71,43 \\
\hline Arbequina & $\mathrm{S}^{\mathrm{a}} / \mathrm{MR}^{\mathrm{b}}$ & 5 & 0 & 0,00 & 1 & 20,00 \\
\hline Aloreña & S & 2 & 0 & 0,00 & 1 & 50,00 \\
\hline Carolea & $\mathrm{S}^{\mathrm{c}}$ & 2 & 0 & 0,00 & 1 & 50,00 \\
\hline Arbosana & $\mathrm{S}^{\mathrm{c}}$ & 1 & 0 & 0,00 & 1 & 100,00 \\
\hline Nabali & $\mathrm{S}^{\mathrm{c}}$ & 1 & 0 & 0,00 & 1 & 100,00 \\
\hline Frantoio & $\mathrm{R}^{\mathrm{a}, \mathrm{b}}$ & 1 & 0 & 0,00 & 0 & 0,00 \\
\hline Total & & 90 & 15 & 16,67 & 52 & 57,78 \\
\hline
\end{tabular}

Referencias: ES: Extremadamente susceptible, S: Susceptible, MR: Moderadamente Resistente, R: Resistente. ${ }^{a}$ Matías et al., 2010, 'López-Escudero y Mercado-Blanco, 2011, ‘ López-Escudero, Martos-Moreno, Raya-Ortega y Blanco-López, 2005.

dPCR-I: juego de cebadores NDf/NDr - INTNDf/INTNDr

ePCR-II: juego de cebadores INTNDf/INTNDr - INTND2f/INTND2r 
Con respecto a la severidad de la sintomatología de VO observada en los olivos muestreados, la prueba PCR-I sólo detectó al patógeno $V$. dahliae en los olivos menos afectados, con severidades 1 y 2 (Tabla 3). Esto podría deberse a que estos niveles de severidad se corresponden con infecciones más recientes, donde el hongo se encuentra en activo crecimiento, pudiendo alcanzar concentraciones elevadas, como se ha observado en otros estudios (Rodríguez-Jurado et al., 1993; Hiemstra y Harris, 1998; Mercado-Blanco et al., 2001; Mercado-Blanco et al., 2003a; Báidez et al., 2007; Markakis et al., 2009). Mercado-Blanco et al. (2003b) lograron detectar al patotipo ND en planta con este juego de cebadores en tejidos severamente afectados, aunque en olivos jóvenes (3 a 5 años), los cuales representan una baja proporción en nuestro muestreo (Tabla 4). Por otro lado, la prueba PCR-II mostró mayor sensibilidad que la prueba PCR-I en todos los niveles de severidades, pudiendo detectar al hongo aún en severidades altas, cuando la concentración del mismo en la planta es mínima, tal como sugieren Mercado-Blanco et al. (2003b).

Con relación a la edad de las plantas, PCRII resultó más efectivo en todas las categorías de edades (Tabla 4). Hasta lo que conocemos, no existen estudios que realicen la detección en planta con infecciones naturales del patotipo ND y abarquen el rango de edades de los olivos aquí incluido.

Para la regresión logística, la variable clasificatoria variedad se agrupó en cuatro estados:
Arauco, Manzanilla, Picual y Otros, que incluyó al resto de variedades con poca representatividad en la muestra (Arbequina, Aloreña, Carolea, Arbosana, Nabali y Frantoio). El análisis indicó que la edad, severidad y variedad no tienen efectos significativos sobre la amplificación ( $p>0,05)$, pudiéndose concluir que la detección en planta del patotipo ND de $V$. dahliae tanto de la prueba PCR-I como PCR-II es independiente de estas variables.

En el ensayo de límite de detección de la técnica, se mezcló ADN de olivo y ADN del hongo para simular una infección natural, y se observaron nuevamente diferencias en el comportamiento de ambos juegos de cebadores. La sensibilidad de PCR-I alcanzó los 20 pg, mientras que para PCR-II aumentó, Ilegando hasta 2 pg. Esto coincide con los resultados obtenidos al analizar las muestras de campo, en donde se observó la misma tendencia, reflejando que PCR-II es más eficiente que PCR-I y por lo tanto permite una mayor detección del patotipo ND de $V$. dahliae en olivos.

\section{CONCLUSIONES}

En el presente trabajo se ajustó un protocolo para PCR anidada empleando por primera vez la combinación de cebadores INTNDf/INTNDrINTND2f/INTND2r (PCR II). Esta prueba mejoró la eficiencia y sensibilidad en la detección del patotipo ND de $V$. dahliae en plantas de olivo con respecto a la combinación comúnmente usada, PCR-I (NDf/NDr - INTNDf/INTNDr). Este método además, es rápido, económico y accesible a la

Tabla 3. Número de muestras positivas y porcentaje de detección, según el nivel de severidad en los olivos muestreados, obtenidos con las combinaciones PCR-I y PCR-II

\begin{tabular}{|c|c|c|c|c|c|}
\hline $\begin{array}{l}\text { Nivel de } \\
\text { Severidad }\end{array}$ & $\mathrm{N}^{\circ}$ de muestras & $\begin{array}{l}\mathrm{N}^{\circ} \text { de muestras } \\
\text { positivas PCR-I }\end{array}$ & $\begin{array}{c}\text { Detección (\%) } \\
\text { PCR-I }\end{array}$ & $\begin{array}{l}\mathrm{N}^{\circ} \text { de muestras } \\
\text { positivas PCR-II }\end{array}$ & $\begin{array}{c}\text { Detección (\%) } \\
\text { PCR-II }\end{array}$ \\
\hline 1 & 49 & 10 & 20,41 & 31 & 63,27 \\
\hline 2 & 23 & 5 & 21,74 & 13 & 56,52 \\
\hline 3 & 10 & 0 & 0,00 & 4 & 40,00 \\
\hline 4 & 8 & 0 & 0,00 & 4 & 50,00 \\
\hline Total & 90 & 15 & 16,67 & 52 & 57,78 \\
\hline
\end{tabular}

Referencias: 1 = 1 a 25\%, 2 = 26 a 50\%, 3 = 51 a 75\% y 4 = 76 a 100\% de tejido foliar afectado (López-Escudero y Mercado-Blanco, 2011).

Tabla 4. Número de muestras positivas y porcentaje de detección, según la edad de los olivos muestreados, obtenidos con las combinaciones PCR-I y PCR-II

\begin{tabular}{cccccc}
\hline $\begin{array}{c}\text { Edad del olivo } \\
\text { (años) }\end{array}$ & $\mathbf{N}^{\mathbf{0}}$ de muestras & $\begin{array}{c}\mathbf{N}^{\mathbf{0}} \text { de muestras } \\
\text { positivas PCR-I }\end{array}$ & $\begin{array}{c}\text { Detección }(\%) \\
\text { PCR-I }\end{array}$ & $\begin{array}{c}\mathbf{N}^{\circ} \text { de muestras } \\
\text { positivas PCR-II }\end{array}$ & $\begin{array}{c}\text { Detección (\%) } \\
\text { PCR-II }\end{array}$ \\
\hline $1-10$ & 2 & 0 & 0,00 & 2 & 100,00 \\
$11-25$ & 37 & 5 & 13,51 & 22 & 59,46 \\
$26-50$ & 41 & 8 & 19,51 & 23 & 56,10 \\
más de 50 & 10 & 2 & 20,00 & 5 & 50,00 \\
Total & $\mathbf{9 0}$ & $\mathbf{1 5}$ & $\mathbf{1 6 , 6 7}$ & $\mathbf{5 2}$ & $\mathbf{5 7 , 7 8}$ \\
\hline
\end{tabular}


mayoría de los laboratorios, ya que utiliza PCR convencional. PCR-II permitió detectar al hongo en bajas concentraciones y en muestras de diversas variedades de olivos, edades de las plantas y niveles de severidad de la enfermedad, lo cual demuestra su fiabilidad. Esta mejora en la metodología para la detección de infecciones naturales de $V$. dahliae permitirá confirmar la presencia del patotipo ND en olivares con síntomas de rama seca, realizar estudios precisos de la incidencia de la VO en la región olivícola argentina, así como diseñar un programa de manejo adecuado para reducir su impacto en la olivicultura. En próximos estudios se podría evaluar su sensibilidad en muestras de olivos asintomáticos, lo cual representaría una gran ventaja en la detección de infecciones incipientes.

\section{AGRADECIMIENTOS}

Los autores agradecen a la Universidad Nacional de Chilecito (UNdeC), al personal de las fincas visitadas y a los extensionistas de EEA-INTA Chilecito, AER- Chilecito, AER-INTA Aimogasta, AER-INTA Capital y SENASA La Rioja. Al Dr. Walter Robledo por su asesoramiento en el análisis de los datos. Al Ing. (M. Sc.) Julio Medvescigh y a los alumnos por acompañarnos al campo.

Financiamiento: Ficyt UNdeC. 292/16, INTA PNVP, INTA/AUDEAS/CONADEV 2016-17

\section{BIBLIOGRAFÍA}

Báidez, A. G., Gómez, P., Del Río, J. A. y Ortuño, A. (2007). Dysfunctionality of the xylem in Olea europaea L. plants associated with the infection process by Verticillium dahliae Kleb. Role of phenolic compounds in plant defense mechanism. Journal of agricultural and food chemistry, 55 (9), 3373-3377. DOI: https:/l doi.org/10.1021/jf063166d

Blanco-López, M. A., Jiménez-Díaz, R. M. y Caballero, J. M. (1984). Symptomatology, incidence and distribution of Verticillium wilt of Olive trees in Andalucía. Phytopathologia Mediterranea, 23, 1-8. Recuperado de: http://www.jstor.org/stable/42684673

Chliyeh, M., Rhimini, Y., Selmaoui, K., Touhami, A. O., Filali-Maltouf, A., Modafar, C. E., ... y Douira, A. (2014). Comparative study of pathogenicity tests for Verticillium dahliae and Phytophthora palmivora causing wilt and decline of olive tree (Olea europaea L.). International Journal of Pure \& Applied Bioscience, 2 (2), 28-38. Recuperado de: http://www.ijpab.com/form/2014\%20 Volume\%202,\%20issue\%202/IJPAB-2014-2-2-28-38.pdf

Collado-Romero, M., Berbegal, M., Jiménez-Díaz, R. M.,
Armengol, J. y Mercado-Blanco, J. (2009). A PCRbased "molecular tool box" for in planta differential detection of Verticillium dahliaevegetative compatibility groups infecting artichoke. Plant Pathology, 58 (3), 515-526. DOI: https://doi.org/10.1111//.13653059.2008.01981.x

Collins, A., Mercado-Blanco, J., Jiménez-Díaz, R. M., Olivares, C., Clewes, E. y Barbara, D. J. (2005). Correlation of molecular markers and biological properties in Verticillium dahliae and the possible origins of some isolates. Plant Pathology, 54 (4), 549-557. DOI: https://doi.org/10.1111/1.13653059.2005.01240.x

Di Rienzo, J. A., Casanoves, F., Balzarini, M. G., Gonzalez, L., Tablada, M. y Robledo, C. W. Infostat (versión 2019) [Software] Córdoba, Argentina: Grupo InfoStat, Facultad de Ciencias Agropecuarias, Universidad Nacional de Córdoba. URL: http://www.infostat.com.ar

Docampo, M. D., Vázquez, A. A. y Laguna, I. G. (1981). Verticillium dahliae Kleb causal de la parálisis parcial del olivo en el área olivera centro oeste Argentina. Revista de Investigaciones Agropecuarias INTA (RIA), 16 (2), 197-204.

Gharbi, Y., Triki, M. A., Jolodar, A., Trabelsi, R., Gdoura, R. y Daayf, F. (2014). Genetic diversity of Verticillium dahliae from olive trees in Tunisia based on RAMS and IGS-RFLP analyses. Canadian Journal of Plant Pathology, 36 (4), 491-500. DOI: https://doi.org/10.10 80/07060661.2014.964776

Gómez del Campo, M., Morales-Sillero, A., Vita Serman, F., Rousseaux, M. C. y Searles, P. S. (2010). El Olivar en los Valles áridos del Noroeste de Argentina (provincias de Catamarca, La Rioja y San Juan). Olivae, 114, 23-45. Recuperado de: http://oa.upm. es/7389/2/Olivar Argentina_Comprimido.pdf

González, V., Rattalino, D., Carrasco, F., Arias, F., Paccioretti, M., Matías, C., ... y Otero, L. (2017). Caracterización de aislamientos de Verticillium dahliae provenientes de la región olivícola argentina. En: Asociación Argentina de Fitopatólogos (Ed.), Libro de Resúmenes $4^{\circ}$ Congreso Argentino de Fitopatología (CAF) (p. 149). Mendoza, Argentina: Asociación Argentina de Fitopatólogos. Recuperado de: http://aafitopatologos.com.ar/wp/wp-content/ uploads/2017/06/Libro-de-res\%C3\%BAmenes4\%C2\%BO-CAF.pdt?05a317

Haelterman, R. M., Tolocka, P. A., Roca, M. E., Guzmán, F. A., Fernández, F. D. y Otero, M. L. (2015). First presumptive diagnosis of Xylella fastidiosa causing olive scorch in Argentina. Journal of Plant Pathology, 97 (2), 391. DOI: http://dx.doi.org/10.4454/JPP. V9712.023

Heinz, R., Lee, S. W., Saparno, A., Nazar, R. N. y Robb, J. (1998). Cyclical systemic colonization in Verticillium- 
infected tomato. Physiological and Molecular Plant Pathology, 52 (6), 385-396. DOI: https://doi. org/10.1006/pmpp.1998.0163

Hiemstra, J. A. y Harris, D. C. (Eds.). (1998). A compendium of Verticillium wilts in tree species. Wageningen, Países Bajos: Ponsen and Looijen.

Intrieri, M. C., Muleo, R. y Buiatti, M. (2007). Chloroplast DNA polymorphisms as molecular markers to identify cultivars of Olea europaea L. Journal of Horticultural Science and Biotechnology, 82, 109-113. DOI: https:/l doi.org/10.1080/14620316.2007.11512206

Jiménez-Díaz, R. M., Cirulli, M., Bubici, G., JiménezGasco, M. del M., Antoniou, P. P. y Tjamos, E. C. (2012). Verticillium Wilt, A Major Threat to Olive Production: Current Status and Future Prospects for its Management. Plant Disease, 96 (3), 304-329. DOI: https://doi.org/10.1094/pdis-06-11-0496

Keykhasaber, M. (2017). Unravelling aspects of spatial and temporal distribution of Verticillium dahliae in olive, maple and ash trees and improvement of detection methods. Disertación doctoral no publicada, Wageningen University, Wageningen: Países Bajos. DOI: http://dx.doi.org/10.18174/396604

Korolev, N., Katan, J. y Katan, T. (2000). Vegetative Compatibility Groups of Verticillium dahliae in Israel: Their Distribution and Association with Pathogenicity. Phytopathology, 90 (5), 529-536. DOI: https://doi. org/10.1094/PHYTO.2000.90.5.529

Ladux, J. L., Jotayan, L., Otero, M. L., González Vera, C. y Ortiz, J. (2014). Incidence of Verticillium dahliae in traditional olive groves in Arauco department, La Rioja Argentina. Acta Horticulturae. (ISHS), 1057, 127-131. DOI: https://doi.org/10.17660/ ActaHortic.2014.1057.14

Ley Nº 22.021 de 1979 (28 de junio de 1979). Régimen especial de franquicias tributarias que tiene por objeto estimular el desarrollo económico de la Provincia de la Rioja. Buenos Aires, Argentina. Recuperado de: http://servicios.infoleg.gob.ar/infoleglnternet/ anexos/30000-34999/32191/norma.htm

Ley $N^{\circ} 8.804$ de 2010 (16 de septiembre de 2010). Emergencia Fitosanitaria por tiempo indeterminado con respecto a la plaga del hongo Verticillium dahliae en las plantaciones de olivos de la Provincia. La Rioja, Argentina: Boletín Oficial de la Provincia de la Rioja No 10.821. Recuperado de: http://www. boletinoflarioja. com.ar/pdf/2010/2010-10-26.pdf

Ley $N^{\circ} 9.489$ de 2013 (11 de febrero de 2014). Zona de Desastre Agropecuario para los departamentos Arauco, General Ortiz de Ocampo y San Blas de los Sauces, afectados por el hongo Verticillium dahliae, conocido como "mal de la rama seca" o "pardeo". La Rioja, Argentina: Boletín Oficial de la Provincia de la Rioja No 11.159. Recuperado de: http://www. boletinoflarioja.com.ar/pdf/2014//2014-03-25.pdf

López-Escudero, F. J., Del Río, C., Caballero, J. M. y Blanco-López, M. A. (2004). Evaluation of olive cultivars for resistance to Verticillium dahliae. European Journal of Plant Pathology, 110, 79-85. DOI: https://doi. org/10.1023/B:EJPP.0000010150.08098.2d

López-Escudero, F. J., Martos-Moreno, C., Raya-Ortega, M. C. y Blanco-López, M. A. (2005). Resistencia del olivo a la Verticilosis causada por Verticillium dahliae. Vida Rural-dossier olivar, 208, 48-54

López-Escudero, F. J. y Mercado-Blanco, J. (2011). Verticillium wilt of olive: A case study to implement an integrated strategy to control a soil-borne pathogen. Plant and Soil, 344, 1-50. DOI: http://dx.doi. org/10.1007/s11104-010-0629-2

Lucero, G., Pizzuolo, P., Boiteux, J. y Hapon, M. V. (2014). Susceptibility of Phytophthora palmivora associated with root disease of some olive trees cultivars. Acta Horticulturae, 1057, 431-436. DOI: https://doi. org/10.17660/ActaHortic.2014.1057.54

Lucero, G., Pizzuolo, P., Linardelli, C., Tarquini, A., Echevarría, S., Otoya Zabala, M. P. y Lucero, H. (2005). Phytophthora y Pythium, dos especies involucradas en la muerte de ramas de olivo. En: Vita Serman, F., Searles, P., Torres, M. (Eds.), XIII Congreso Latinoamericano de Fitopatología. III Taller Argentino de Fitopatología (p. 436). Villa Carlos Paz. Córdoba, Argentina.

Lucero, G., Vettraino, A. M., Pizzuolo, P., Stefano, C. D. y Vannini, A. (2007). First report of Phytophthora palmivora on olive trees in Argentina. Plant Pathology, 56 (4), 728. DOI: https://doi.org/10.1111/j.13653059.2007.01588.x

Ma, Z. y Michailides, T. J. (2007). Approaches for eliminating PCR-Inhibitors and designing PCR primers for the detection of phytopathogenic fungi. Crop Protection, 26 (2), 145-161. DOI: https://doi. org/10.1016/i.cropro.2006.04.014

Matías, A. C., Toro, A. A., Molina, M. S., Montalván, L. D., Ortiz, P. del V., Aybar, V., ... y Mamaní, R. E. (2010). Variedades de olivo cultivadas en las provincias de Catamarca y La Rioja, Argentina. Buenos Aires, Argentina: Instituto Nacional de Tecnología Agropecuaria. Recuperado de: https://inta.gob.ar/ sites/default/files/variedades_de_olivo.pdf

Markakis, E. A., Tjamos, S. E., Antoniou, P. P., Paplomatas, E. J. y Tjamos, E. C. (2009). Symptom development, pathogen isolation and Real-Time QPCR quantification as factors for evaluating the resistance of olive cultivars to Verticillium pathotypes. European Journal of Plant Pathology, 124, 603. DOI: https://doi.org/10.1007/ s10658-009-9447-X

Mercado-Blanco, J., Collado-Romero, M., ParrillaAraujo, S., Rodríguez-Jurado, D. y Jiménez-Díaz, R. 
M. (2003a). Quantitative monitoring of colonization of olive genotypes by Verticillium dahliae pathotypes with real-time polymerase chain reaction. Physiological and Molecular Plant Pathology, 63 (2), 91-105. DOI: https://doi.org/10.1016/i.pmpp.2003.10.001

Mercado-Blanco, J., Collado-Romero, M., Rodríguez Jurado, D. y Jiménez-Díaz, R. M. (2005). Aplicación de técnicas moleculares para determinar la incidencia y extensión de la colonización de plantas de olivo por los patotipos de Verticillium dahliae. Olivae, 104, 36-45.

Mercado-Blanco, J., Rodríguez-Jurado, D., ParrillaAraujo, S. y Jiménez-Díaz, R. M. (2003b). Simultaneous Detection of the Defoliating and Nondefoliating Verticillium dahliae Pathotypes in Infected Olive Plants by Duplex, Nested Polymerase Chain Reaction. Plant Disease, 87 (12), 1487-1494. DOI: https://doi. org/10.1094/PDIS.2003.87.12.1487

Mercado-Blanco, J., Rodríguez-Jurado, D., Pérez-Artés, E. y Jiménez-Díaz, R. M. (2001). Detection of the non defoliating pathotype of Verticillium dahliae in infected olive plants by nested PCR. Plant Pathology, 50 (5), 609-619. DOI: https://doi.org/10.1046/j.13653059.2001.00601.x

Mercado-Blanco, J., Rodríguez-Jurado, D., PérezArtés, E. y Jiménez-Díaz, R. M. (2002). Detection of the defoliating pathotype of Verticillium dahliae in infected olive plants by nested PCR. European Journal of Plant Pathology, 108, 1-13. DOI: https://doi. org/10.1023/A: 1013994827836

Milligan, B.G., 1992. Plant DNA isolation. En: Hoelzel, A. R. (Ed.), Molecular Genetic Analysis of Populations: A Practical Approach (59-88). Oxford, Reino Unido: IRL Press.

Montes, F., Páez, J. I., Vega, J. M. y Duhart, M. E. (1997). Épocas de aislamiento de Verticillium dahliae Kleb en olivar en la provincia de Sevilla. Boletín de Sanidad Vegetal. Plagas, 23, 439-447.

Nazar, R. N., Hu, X., Schmidt, J., Culham, D. y Robb, J. (1991). Potential use of PCR-amplified ribosomal intergenic sequences in the detection and differentiation of verticillium wilt pathogens. Physiological and Molecular Plant Pathology, 39, 1-11. DOI: https://doi.org/10.1016/0885-5765(91)90027-F

Otero, M. L. (2005). Detección de Verticillium dahliae Kleb en olivos infectados de la zona olivarera del noroeste mediante pruebas serológicas y moleculares. Tesis doctoral no publicada. Facultad de Ciencias Exactas, Universidad Nacional de Córdoba. Córdoba, Argentina.

Pegg, G. F. y Brady, B. L. (2002). Verticillium wilts. Wallingford, UK: CABI Publishing. DOI: 10.1079/9780851995298.0002

Pérez-Artés, E., García-Pedrajas, M. D., Bejarano-
Alcázar, J. y Jiménez-Díaz, R. M. (2000). Differentiation of cotton-defoliating and nondefoliating pathotypes of Verticillium dahliaeby RAPD and specific PCR analyses. European Journal of Plant Pathology, 106, 507-517. DOI: https://doi.org/10.1023/A:1008756307969

Pérez, B. A., Barreto, D., Docampo, D., Otero, L., Costilla, M., Roca, M. y Babbitt, S. (2001). Current status of the drying syndrome (seca) of olive trees in Argentina. Phytopathology, 91 (6), S71.

Pérez, B. A., Farinon, O. M. y Berretta, M. F. (2011). First Report of Fusarium solani causing Root Rot of Olive in Southeastern Argentina. Plant Disease, 95 (11), 14761476. DOI: https://doi.org/10.1094/pdis-02-11-0095

Pérez, B. A., Otero, M., Oriolani, E. J. A., Roca, M., Brancher, N. y Matías, A. C. (2010). Update on olive pathologies in Argentina. En: APS Annual Meeting 2010 (S99). Charlotte, Estados Unidos: American Phytopathological Society

Rattalino, D. L., Moriconi, D. N., Rivera, P. M., González, V., Paccioretti, M. y Otero, M. L. (2018). Rama Seca en olivares de la provincia de La Rioja: prevalencia, incidencia y su relación con la presencia del patógeno Verticillium dahliae Kleb. Horticultura Argentina, 37 (94), 128. Recuperado de: http://www.horticulturaar. com.ar/bajar. php?archivo=201812061636490.3.resumenes-de-fruticultura-final. pdf\&nombre=Res $\%$ C 3\%BAmenes $\% 20$ de $\% 20$ Fruticultura \% 20-\%20XL\%20Congreso\% 20 Argentino\%20de\%20Horticultura

Roca, M., Docampo, D., Otero, M., Babbitt, S., Barreto, D., Costilla, M., ... y Guchea, F. (2001). La rama seca en olivares de la provincia de La Rioja. Revista Sociedad Argentina de Horticultura, 20 (48), 58.

Roca, M. M. (2015). "Revisión de antecedentes, presencia, incidencia, severidad, frecuencia de agentes asociados y mermas de rendimiento para 'rama seca' del olivo en la provincia de La Rioja." Tesis de maestría no publicada. Facultad de Ciencias Agrarias y Forestales, Universidad Nacional de La Plata. Buenos Aires, Argentina. DOI: https://doi. org/10.35537/10915/59879

Rodríguez-Jurado, D. (1993). Interacciones huéspedparásito en la marchitez del olivo (Olea europaea L.) inducida por Verticillium dahliae Kleb. Tesis Doctoral no publicada, Universidad de Córdoba, Córdoba, España

Rodríguez-Jurado, D., Blanco-López, M. A., Rapoport, H. F. y Jiménez-Díaz, R. M. (1993). Present status of Verticillium wilt of olive in Andalucía (southern Spain). EPPO Bulletin, 23(3), 513-516. DOI: https://doi. org/10.1111/j.1365-2338.1993.tb01362.x

Sánchez-Hernández, M. E., Pérez de Algaba, A., BlancoLópez, M. A. y Trapero-Casas, A. (1998). La "seca" de olivos jóvenes I: Sintomatología e incidencia de los 
agentes asociados. Boletín Sanidad Vegetal - Plagas, 24 (3), 551-572. Recuperado de: https://www.mapa. gob.es/app/publicaciones/art datos. asp?articuloid $=8$ 58\&codrevista $=$ Plagas

Saponari, M., Boscia, D., Nigro, F. y Martelli, G. P. (2013). Identification of DNA sequences related to Xylella fastidiosa in oleander, almond and olive trees exhibiting leaf scorch symptoms in Apulia (Southern Italy). Journal of Plant Pathology, 95(3). DOI: https:/l doi.org/10.4454/JPP.V95I3.035

Schnathorst, W. C. y Sibbett, G. S. (1971). Relation of strains of Verticillium albo-atrum to severity of Verticillium wilt in Gossypium hirsutum and Olea europaea in California. Plant Disease Reporter, 9, 780-782.

Searles, P., Rousseaux, M.C., Ladux, J., Trentacoste, E., Arjona, C., Colica, J., ... y Vita Serman, F. (2012). Following olive footprints in Argentina. Scripta horticulturae 13(13-23).

Smith, H. C. (1965). The morphology of Verticillium alboatrum, V. dahliae, and V. tricorpus. New Zealand Journal of Agricultural Research 8(3), 450-478. DOI: https://doi.org/10.1080/00288233.1965.10419889

Tosi, L. y Zazzerini, A. (1998). Investigation on the epidemiology of Verticillium wilt in central Italy. Olivae, 71, 50-55.

Trapero, C., Rallo, L., López-Escudero, F. J., Barranco, D. y Díez, C. M. (2015). Variability and selection of Verticillium wilt resistant genotypes in cultivated olive and in the Olea genus. Plant Pathology, 64(4), 890900. DOI: https://doi.org/10.1111/ppa.12330

Wilson, I. G. (1997). Inhibition and facilitation of nucleic acid amplification. Applied and Environmental Microbiology, 63(10), 3741-3751. Recuperado de: https://aem.asm.org/content/63/10/3741 